\title{
The Relation between Linguistic Skills, Personality Traits, and Language Anxiety
}

\author{
Salim Abu-Rabia, Yefat Peleg, Wael Shakkour \\ Faculty of Education, University of Haifa, Mt. Carmel, Haifa, Israel \\ Email: Salimar@construct.haifa.ac.il
}

Received 5 November 2013; revised 7 December 2013; accepted 15 December 2013

Copyright (C 2014 by authors and Scientific Research Publishing Inc.

This work is licensed under the Creative Commons Attribution International License (CC BY). http://creativecommons.org/licenses/by/4.0/

\section{Abstract}

This study examines the relation between linguistic skills, personality types, and language anxiety amongst eighty Israeli Grade 11 students whose mother tongue is Hebrew and who are learning English as a second language. The participants were administered various tests measuring their basic linguistic skills in Hebrew as their first language (L1), including phonological and morphological awareness, working memory, rapid naming-and a series of language tests: vocabulary, word and text reading, pseudo-word reading, and spelling. They were also administered tests in English as a foreign language (EFL): vocabulary, word recognition, letter identification, text reading, and pseudo-word reading. All the participants completed an anxiety questionnaire with respect to both language sets, together with a personality questionnaire based on the Big Five model. The findings demonstrated a significant positive correlation between all the $L 1$ and EFL linguistic skills. A significant negative correlation was obtained between the linguistic skills in both languages and anxiety towards English and Hebrew. The participants also exhibited similar levels of anxiety towards both languages. The results further identified the contribution made by personality types-neuroticism in particular-to the prediction of language anxiety and EFL success. All the findings are discussed in light of the literature, suggestions being made for future research possibilities.

\section{Keywords}

Anxiety; L1 and L2 Anxiety; Transfer of Skills; Personality Traits and Anxiety

\section{Introduction}

Under the influence of the recently-growing trend towards "multi-lingualism" evident in many countries, the acquisition of a foreign language ( $\mathrm{FL}=\mathrm{L} 2)$ has become a central goal both in elementary education and aca- 
demic frameworks. Alongside the discussion of various aspects lying at the heart of language acquisition, increasing attention is being paid to the issue of the anxiety attendant upon learning L2 - its sources, implications, and various methods for dealing with it. A lack of clarity also exists due to the contradictory findings provided by studies in the field - together with the divergent approaches adopted by their authors. While one school regards L2-induced anxiety as a contributing factor to language-learning failure (Horwitz, Horwitz, \& Cope, 1986), another views anxiety as the by-product of the retardation of L2 acquisition due to weak mother-tongue (MT) skills (Ganschow \& Sparks, 1993, 1996). Successful L2 acquisition thus appearing to be dependent upon numerous causes, research integrating the various methods and diverse variables is called for.

A further subject requiring examination is the relation between the learner's personality type and languageacquisition anxiety. As noted above, the majority of studies conducted to date have looked at the system of personal variables involved in acquiring a language and L2 communicative competence (Ehrman \& Oxford, 1995; MacIntyre \& Charos, 1996) rather than L2-induced anxiety. The importance of analyzing this field is thus clear - in particular, the question of whether L2 anxiety is an independent phenomenon or forms part of a broader entity associated with a specific personality type. In light of this, the present study which integrates linguistic and personality aspects hopes to deepen our understanding of the variables connected with L2 anxiety. It also addresses a further issue yet to be studied, namely, the anxiety induced by L1 language assignments. This is discussed as part of an examination of the relation between this anxiety and L1 linguistic skills and anxiety with respect to L1 and EFL amongst Hebrew-speaking high-school students.

\section{Theoretical Background}

L2 acquisition is a complex process that involves cognitive, demographic, and emotional (motivation, attitudes, anxiety) aspects as well as L1 skills (written and oral language), that directly impact a student's linguistic capacity to acquire other languages (Abu-Rabia, 2004; Ganschow, Sparks, Anderson, Javorsky, Skinner, \& Patton, 1994; Onwuegbuzie, Bailey, \& Daley, 2000). Not constituting an abstract task of learning/remembering a set of words and applying grammatical rules, learning L2 demands a personal commitment. At its base lies meaningful communication and the effective transmittal of message via various unfamiliar syntactical, semantic, and phonological means. The student must also cope with the tension and ambivalence deriving from the unknown culture to which the language belongs (Horwitz, 1995; Verhoeven \& Vermeer, 2002). Despite the fact that many students exhibit a motivation to develop their capacity to communicate in a foreign language, they report the emergence of a level of anxiety when beginning to learn that directly affects their success or failure (Onwuegbuzie, Bailey, \& Daley, 2000).

\subsection{L2 Anxiety}

L2 anxiety is a unique and complex phenomenon comprised of numerous dimensions, defined as a feeling of stress and/or fear that accompanies the acquisition of L2 skills such as speaking, listening and learning (MacIntyre \& Gardner, 1994). In contrast to the many scholars who have examined language anxiety in general, Horwitz, Horwitz, \& Cope (1986) were the first to contend that L2 anxiety must be defined separately and its influence on the learning process assessed directly. This study regards L2 anxiety as a separate entity of independent views, beliefs, feelings, and behaviors associated with learning a language in class that are aroused by the uniqueness of the process of acquiring a new language.

The first dimension is communication apprehension. This relates to the anxiety induced in interpersonal situations and is connected to vocabulary and its retrieval. Communication in a L2 requires taking chances, some of the linguistic rules being unfamiliar to the learner. In this light, speech-especially when facing a large audience - constitutes the highest stress factor. The second element is test anxiety, which occurs primarily when the questions on a test have been less well studied and are of an ambivalent nature. The third component is the fear of negative evaluation. Overall, anxious students have low self-esteem and a negative self-view. Not feeling confident in their abilities, they shy away from conversation, are passive in class, and avoid participating in class activities (Gregersen \& Horwitz, 2002). Despite understanding that correction is necessary for learning, their sense of anxiety increases when the teacher points out their mistakes (Horwitz et al., 1986).

Horwitz et al. (1986) have constructed a unique questionnaire for measuring L2 anxiety—namely, the Foreign Language Classroom Anxiety Scale (FLCAS). Based on self-reporting, this assesses the level of anxiety induced in the student learning L2. It includes thirty-three items ranked on a 5-point Likert scale ranging from 
"absolutely agree" to "completely disagree." These reflect the three types of anxiety comprising L2 anxiety. The questionnaire is well accepted in the literature, serving many scholars as a statistical tool. Its internal reliability is high $(\mathrm{a}=.93)$, as are its repeat-test reliability $(\mathrm{r}=.83)$ and frequency level (Horwitz, 1991; Horwitz \& Young, 1991), significant matches existing between each of the items and the overall anxiety mark.

Two approaches towards the study of L2 anxiety can be adduced in the literature. The first, which focuses on cognitive, emotional, demographic, and personality aspects, perceives L2 anxiety as a separate entity of views, beliefs, and behaviors linked to the study of a language in class and serving a contributory factor to failure (Horwitz et al., 1986; MacIntyre \& Gardner, 1994; Onwuegbuzie, Bailey, \& Daley, 1999a; Phillips, 1992). The second, promoted by Ganschow \& Sparks $(1993,1996)$, addresses linguistic aspects, proposing that L2 anxiety is a by-product of weak L1 linguistic skills.

\subsection{L2 Anxiety as a Cause}

Various scholars (MacIntryre \& Gardner, 1994; Tobias, 1979) have posited that L2 anxiety occurs at three stages during the learning process - input, processing, and output. L2 anxiety during the first stage is experienced by students who are exposed to a new stimulus, word, or sentence in the L2, being linked to their self-orientation, concentration, and assimilation of a new stimulus levels. A high level of anxiety reduces the number of stimuli preserved in the memory for future processing or retrieval, thereby impeding the learning process. The processing stage requires the organization, storage, itemization, and elaboration of new material. Anxiety at this stage relates to the student's fear while performing actions according to an external stimulus, its level depending on the complexity of the stimulus, scope of memory required, and level of organization of the material presented. A high level of anxiety is liable to interfere with the cognitive processing of basic tasks, thus impairing the understanding of messages and/or the learning of new vocabulary in L2. Anxiety at the output stage is experienced when the student is required to demonstrate ability to implement the material learned based on the previous two stages. A high level of anxiety is liable to retard speaking and writing skills in L2. Students who experience anxiety at one stage were at high risk of experiencing it at the other two stages, indicating that it is accumulative (Onwuegbuzie, Bailey, \& Daley, 1999a).

L2 anxiety effects a student's ability to process information in L2, reducing his response rate to linguistic input. Such students avoid conveying messages in L2, forget vocabulary and syntactical rules, mispronounce words, find it difficult to retrieve new words, and are slow learners and low achievers. Their behavior is characterized by low class attendance rates, homework avoidance, and reticence in class discussions, their conversation being marked by short sentences and restricted syntactical usages (Horwitz et al., 1986; MacIntyre \& Gardner, 1991; Phillips, 1992; Price, 1991). Physiological symptoms of anxiety express themselves in headaches, stomachache, sweating, shaking, weeping, and irritable behavior (von Wörde, 2003). Studies have demonstrated a negative relation between anxiety and high-school and college grades (Gardner, Lalonde, Moorcroft, \& Evers, 1987), vocabulary production, oral-exam performance (Phillips, 1992), written expression, and reading-comprehension skills (Argaman \& Abu-Rabia, 2002).

The effect of anxiety upon the learning process can be explained by the Cognitive Attentional Interference Model (Wine, 1980), according to which anxiety constitutes a cognitive disorder because it distracts attention to irrelevant elements when assessing new situations. This in turn reduces ability to apply new knowledge to the solving of a specific problem due to the difficulty in remembering information or ineffective use of problemsolving strategies - the disorder caused by the anxiety eventually leading to an impairment in performance.

The function of anxiety in the learning context can also be explained by the Coping Strategies Model (Bailey, Onwuegbuzie, \& Daley, 2000), which distinguishes between effective and ineffective learning habits. According to this model, at least part of the disturbance in L2 linguistic performance in anxiety-ridden students is linked to deficient coping strategies - including ineffective time allocation that prevents them from covering all the material learned, a lack of sleep that makes them tired when learning at home and in the classroom, and the taking of numerous breaks which makes starting difficult and thus impedes the learning process.

Scholars who have examined the characteristics exhibited by students who display a high level of anxiety at each stage of the learning process have found that, in the majority of cases, they are older in age, come from a mono-lingual background, and have a low self-image (Ohata, 2005) and low expectations of success in acquiring L2, low academic competence, a low intellectual capacity, a low rate of work effectiveness, and insufficient experience in learning L2-alongside minimal visits to foreign countries (Levine, 2003; Onwuegbuzie, Bailey, 
\& Daley, 1999b, 2000; Rodriguez \& Abreu, 2003). A significant relation also exists between L2 anxiety and achievement at the various stages of learning (MacIntyre \& Gardner, 1994). The level of anxiety predicted future language performance, explaining between $10.5 \%$ and $40 \%$ of the performance variance, in fact (Onwuegbuzie, Bailey, \& Daley, 1999a, 1999b).

Studies have shown that anxiety is directly related to the Grade in which the student is studying. First and second graders exhibit a lower level of anxiety, third graders reporting a higher level. Scholars explain this circumstance by the fact that these students were a priori classified as facing less expectations, together with a negative L2 experience at school that heightened their anxiety level and drove them to postpone learning L2 until later (Onwuegbuzie, Bailey, \& Daley, 1999b). In advanced classes, more complex material was learned with respect to vocabulary and grammatical difficulty, teachers also making greater use of the target language (Casado \& Dereshiwsky, 2001).

The level of anxiety has been found to be related to the nature of the exams given in L2 courses. Students reported that oral exams conducted face to face with the examiner aroused greater anxiety than written tests. At the same time, the response to exams altered depending on the level of preparation and L2 verbal competence (Madsen, Brown, \& Jones, 1991). In distinction, Phillips' study demonstrated that all the students interviewed reported anxiety and discomfort during oral examinations, despite having prepared thoroughly for the test. These feelings were characteristic of both high- and low-ability students, the high-achieving students even employing more dramatic descriptions. One variable found to influence the level of anxiety was the classroom atmosphere-including the teacher-student relationship and the level of support given by the teacher parallel to the level of the student's sense of belonging and involvement in the class (Horwitz, 2000; von Wörde, 2003).

In contrast to the majority of studies in the field, which focus on the spoken aspects of language (speaking and listening) as arousing anxiety, Saito, Garza, \& Horwitz (1999) stress the existence of anxiety induced by L2 reading, distinguishing this from general language anxiety. They note two facets of $\mathrm{L} 2$ reading that are liable to induce anxiety: a) an unfamiliar text or writing system, both of which reduce the reader's ability to rely on a specific and familiar system of letter-sound relationship in the process of decipherment and thus inevitably increase his level of anxiety while reading; and b) material that is culturally unfamiliar and thus does not transmit a logical or intelligible message to the reader. They found that, in distinction to general L2 anxiety, which can exist at various levels irrespective of any specific language, L2 reading anxiety alters in level depending on the language being learned - the complexity of the writing system creating a particular and idiosyncratic challenge to the reader.

\subsection{Anxiety and Personality Types}

The few studies that have examined the personality variable in language acquisition have primarily focused on the student's communication skills. Ehrman \& Oxford (1995) have demonstrated that a L2 high-achiever exhibits a critical-thinking aptitude, cognitive flexibility, and intuitive thought processes. It has also been shown that personality variables affect the choice of learning style and response to the learning situation. Another study (Gregersen \& Horwitz, 2002) investigated the relation between L2 anxiety and perfectionist traits, the findings indicating that perfectionists set standards of performance that are accompanied by a high self-criticism level, expecting themselves to achieve L2 fluency without mistakes or mispronunciation. Fearing a less-than-excellent performance or negative assessment by others, they avoid communication with others until they are confident that they can express themselves perfectly. This type of personality typically experiences language anxiety. The study's results demonstrate that, in contrast to students with low levels of anxiety, those with high levels reported expecting high standards of themselves, submitting work late, apprehension regarding others' opinions, and fear of making mistakes. They thus support the existence of common features between anxious and perfectionist students.

Another study (MacIntyre \& Charos, 1996) employed the Big Five personality model (Costa \& McCrae, 1992) in examining personality types amongst students and their ability to predict L2 communication competence. This model, which is prevalent in personality studies, is based on five personality structures that contain specific qualities.

1. Extroversion/introversion: The extrovert exhibits a real interest in people and events, an ability to enjoy, assertiveness, activeness, a desire to communicate, and emotional feelings - the introvert preferring to remain alone and be non-active in seeking to communicate. 
2. Agreeableness: This personality type exhibits compassion, niceness, gentleness, confidence in others, trust, and warmth (vs. antagonism, aggressiveness, and non-cooperation).

3. Conscientiousness: The type is characterized by a high level of organization and perseverance during taskoriented activities. At one end of the scale lies diligence, responsibility, and achievement, at the other laziness, spontaneity, and unreliability.

4. Neuroticism: This personality dimension is defined by lack of stability, worry, fear, depression, and mood swings (vs. emotional stability, calmness, confidence, contentment, and coping with stress).

5. Openness to experience: At the one end of this scale lie creativity, imagination, rapid grasp, and consideration - at the other, conservatism, conventionality, and lack of curiosity.

The findings of this study point to a relation between the various personality types and L2 communication competence. A significant positive relation obtained between agreeableness and the desire to communicate, amiable and social types seeking to establish social contacts in the L2. Significant positive relations were also found to exist between openness to experiences and self-ability perception in learning a L2 and between level of organization and a positive attitude towards the learning situation. With respect to anxiety, a significant negative relation obtained between emotional stability/extroversion and anxiety, extroverts or emotionally-stable people experiencing little anxiety and being more involved in L2 social interactions. The conclusions drawn by the authors were that personality variables affect attitudes towards language learning and competence, language anxiety, and learning motivation.

\subsection{L2 Anxiety as a Consequence}

Ganschow and Sparks $(1993,1996)$ contend that it is important to relate to the basic linguistic skills a student possesses in her/his L1 as well as her/his L2 abilities when examining L2 anxiety. Positing the existence of linguistic coding variances, they suggest that linguistic competence lies on a scale, interpersonal variances in basic linguistic skills (phonology, orthography, syntax, and semantics) serving as the basis for L2 acquisition. They also stress the significance of the aptitude component in learning languages, which is comprised of four variables: phonological coding competence (the capacity to learn, identify, and remember relationships between specific sounds and their graphic representation), syntactical sensitivity (familiarity with the syntactical function of words or other components in a sentence and the application of grammatical rules), inductive linguistic aptitude (the ability to infer linguistic rules, forms, and patterns from new linguistic content), and oral learning and memorization competence (the capacity to learn quickly and to store numerous phonetic and grammatical relationships in the memory) (Sparks, Ganschow, Kenneweg, \& Miller, 1991). They further argue that deficiency in linguistic-coding competence leads to interpersonal disparities in language acquisition — rather than emotional variables (motivation, anxiety, etc.).

Support for Ganschow and Sparks' theory is found in Cummins' thesis $(1979,1989)$ regarding the transfer of interlingual skills, according to which reading-level and competence in L2 depends on the student's cognitive and academic aptitude level in L1. In other words, skills being transferable from one language to another, the greater ability a student possesses in L1, the easier he will find it to transfer these skills to L2. In his studies, Cummins demonstrates that participants who had difficulty reading in L1 also found the same reading components challenging in $\mathrm{L} 2$.

The various studies conducted by Ganschow and his colleagues (Ganschow, Sparks, \& Javorsky, 1998; Sparks \& Ganschow, 1993; Sparks, Ganschow, \& Javorsky, 2000; Sparks, Javorsky, Ganschow, Pohlman, \& Patton, 1992) evince the existence of significant variances in the phonological and orthographic skills of successful and struggling L2 students. In contrast to the latter, the high-achievers exhibited good speaking and writing abilities in L1 as well as an aptitude for learning languages. These discrepancies were manifest in both high-school and tertiary education. While no semantic disparities in vocabulary or reading comprehension in the students' L1 were evident, grammatical difficulties were apparent in some cases. The researchers thus concluded that the emotional difficulties were the consequence of difficulties in L1. Taking a sample of students with and without learning disabilities, they found that both groups exhibited a similar level of motivation in L2. The findings of a study that divided students into groups on the basis of the level of risk of developing learning disabilities/existent learning disabilities demonstrated that each group exhibited a similar level of anxiety in L2. In addition to the various levels of anxiety found to be a function of L1 learning skills, they also supported the authors' conclusion that linguistic skills explain a substantial degree of the variance in L2. 
In examining the relation between L2 anxiety and linguistic skills, they found that those students with a low level of L1 aptitude who were also L2 low-achievers were characterized by a high level of anxiety-in comparison with those who were high achievers. The various studies conducted also evinced disparities in L1 conversational and writing indices - as well as in language-learning aptitude - between the groups exhibiting divergent levels of anxiety. Thus despite the similarity in psychometric grades, IQ level, and overall grade average of students exhibiting various levels of anxiety, variances obtained in performance in tasks measuring spoken language (listening and conversation), phonological processing (phonetic analysis, word identification), and L2 learning aptitude.

In one of his studies, Abu-Rabia (2004) found a significant positive relation to exist between the grades in a Hebrew-comprehension (L1) assignment and those in an English-comprehension (L2) assignment. In contrast to other studies, this also anticipated a negative relation between the grades obtained in a L1 reading-comprehension assignment and the level of L2 anxiety. Examination of the relation between L2 skills and the level of anxiety with respect to L2 revealed the existence of a negative relation between spelling competence/L2 readingcomprehension grade and the level of anxiety with regard to English. Abu-Rabia concluded that the acquisition of language skills in L1 also has a direct effect upon linguistic development in relation to other languages and that a relation obtains between L2 anxiety and L1 language aptitude.

\section{Research Questions}

1. Is there a relationship between $\mathrm{L} 1$ anxiety and $\mathrm{L} 2$ anxiety?

2. Is there a relationship between L1/L2 language skills and L1/L2 anxiety?

3. Is there a relationship between personality types and L1/L2 anxiety?

\subsection{Hypotheses}

1. There will be a positive correlation between L1 and L2 skills: The better L1 skills are the higher L2 skills will be.

2. A negative relation will be found between L1 skills and the level of anxiety towards L1: The higher the L1 skills, the lower the level of anxiety will be. Similarly, a negative relation will obtain between L2 skills and the level of anxiety felt towards L2. I.e., the higher the L2 skills, the less anxiety will be felt towards L2.

3. There will be a positive relationship between the level of L1 anxiety and the level of L2 anxiety.

4. There will be a relationship between personality types and the level of anxiety felt with respect to L1 and L2.

\subsection{Methodology}

\subsubsection{Participants}

The sample population was taken from eleventh graders in regular schools who are native Israelis and mothertongue Hebrew speakers studying EFL. 80 students participated from four regular high schools in the north of the country-31 boys and 49 girls between sixteen and seventeen years of age. All of them were taking English as a compulsory subject, although at different levels: $2.5 \%$ were taking 1 unit, $6.3 \% 3$ units, $42.5 \% 4$ units, and $48.5 \% 5$ units. All the participants came from a middle socio-economic background. $15.9 \%$ had never been out of the country. $32.5 \%$ had visited a foreign country twice, $40 \%$ had made up to nine visits, and $12.6 \%$ had been abroad more than ten times.

\subsubsection{Tools}

1. A L2 anxiety questionnaire-the Foreign Language Classroom Anxiety Scale (FLCAS) (Horowitz et al., 1986), which assesses the level of anxiety a student experiences during the learning of L2. The questionnaire consists of a graded series of thirty-three items, the participant noting the degree to which he agrees with the statement on a scale of 5 , from "completely disagree" to "absolutely agree." The questionnaire was translated into Hebrew, its level of internal reliability being $\mathrm{a}=.84$.

2. A demographic questionnaire that included questions relating to age, gender (male/female), socio-economic level (low, middle, high), number of prior visits to a foreign country, number of English units being taken, and the student's current grade in English on a scale of 100. Due to the fact that each participant's absolute score in English is meaningless in its own right, a relative score was calculated (including English) that accurately re- 
flects the student's competence. This score was the total of each participant's scores in relation to the number of units he was studying and his score in relation to all the participants. A Pearson correlation analysis indicates that a significant positive relation exists between a relative score including English and an English score in relation to the number of units studied $(\mathrm{r}=.972, \mathrm{p}<.01)$, an English score in relation to all the participants $(\mathrm{r}=.973$, $\mathrm{p}<.01)$, and an English score $(\mathrm{r}=.973, \mathrm{p}<.01)$.

3. A personality questionnaire based on the Big Five model — the Revised NEO Personality Inventory (Costa \& McCrae, 1992). The questionnaire was translated into Hebrew by Montague (1993). The questionnaire exists in two versions developed by these researchers, both possessing a high internal validity and reliability level, as set out in the test manual. The first is a longer version that consists of 243 items that describe behaviors, emotions, and tenets and measure the five personality types. The second - used in the present study - consists of 60 items selected from the full questionnaire (see Appendix). The participant signals the degree to which he agrees with the statement on a 5-point scale, from 0 ("completely disagree") to 5 ("absolutely agree"). Each personality dimension is scored separately, being calculated as the total of each participant's answers to the items relating to his type. This score serves as the basis for the construction of a personality profile, graded according to five levels: very low, low, middling, high, and very high. Separate scales are given for male and female participants, as set out in the test manual.

- Items 1, 6, 11, 16, 21, 26, 31, 36, 41, 46, 51, and 56 represent the neurotic type. A high score $=$ a high level of neuroticism. The internal reliability level of the items is a $=.85$.

- Items 2, 7, 12, 17, 22, 27, 32, 37, 42, 47, 52, and 57 represent the extrovert type. A high score $=$ an extremely extrovert type. The internal reliability level of the items is $\mathrm{a}=.61$.

- Items $3,8,13,18,23,28,33,38,43,48,53$, and 58 represent the openness-to-experiences type. A high score $=$ an open type. The internal reliability level of the items is $\mathrm{a}=.66$.

- Items 4, 9, 14, 19, 24, 29, 34, 39, 44, 49, 54, and 59 represent the agreeable type. A high score $=$ an agreeable type. The internal reliability level of the items is a $=.70$.

- Items $5,10,15,20,25,30,35,40,45,50,55$, and 60 represent the conscientious type. A high score $=$ a conscientious type. The internal reliability level of the items is $\mathrm{a}=.85$.

5. A vocabulary sub-test from the Wechsler Intelligence Scale for Children (Hebrew version-Lieblich, Ben Shahar-Segev, \& Ninio, 1976), a test that examines the participant's production and conceptualization abilities via a scale of 24 items that demand different levels of abstraction-functional-concrete, in which the participant must adduce the primary use of the item (e.g., "What is a knife?"), and abstract (e.g., "What is hesitation?"). The test is stopped after five consecutive mistakes. The participant can earn a score of 0 (wrong answer), 1 (partial answer), 2 (full answer) for each item, the score being given according to an explicit guide and thus not requiring any reliability test. This assignment assesses the percent accuracy-i.e., the total score gained by the participant in relation to the maximum possible score (48 points).

6. Assignments examining Hebrew reading and writing abilities, together with assignments assessing the language skills that lie at their base, used in the learning-disability-diagnosis clinic at the University of Haifa. The method of administration of the assignments and their coding are explicitly learned so that every tester administers and grades the assignment in identical fashion. The assignments have a high reliability and validity level (Shany, Ben Dror, \& Zeiger, 1997; Shany, Zeiger, \& Ravid, 2001).

a) Phonological awareness - a phonemic omission test (Shany, Ben Dror, \& Zeiger, 1997; Shany, Zeiger, \& Ravid, 2001) that examines the participant's awareness of the sound structure of the spoken language via the omission of phonemes in spoken words. For example, "Pronounce the word 'halom' without the letter 'l'." The test consists of 20 words, the percent accuracy being measured in each assignment (total of correct answers from all the items).

b) The rate of verbal information-processing: RAN tests (rapidity of retrieval of verbal markers for visual stimuli) (Shany, Ben Dror, \& Ravid, 1997; Shany, Zeiger, \& Ravid, 2001). These test the rate at which the participant is able to retrieve verbal information stored in long-term memory via the identification of letters and numbers. The rate is measured in seconds (see Appendix 7).

c) Morpho-grammatical awareness (a section from a tailored Language matriculation exam) - a test in which the participant is asked to complete ten defective verbs in a passage by means of given roots, based on the context. For example, "The teacher hitchashev (was considerate of) the student (h-sh-v)." The answer is given in the examiner's manual. This test examines percent accuracy (total of correct answers from all the items).

d) Verbal working memory: repetition of completed verbs (Shany, Ben Dror, \& Ravid, 1997; Shany, Zeiger, \& Ravid, 2001). This test assesses the participant's working memory by asking him to complete words in sen- 
tences and then repeat them in order. The test is graded so that the number of words to be repeated increases from two to six (six sentences). Each stage consists of two sub-stages. Both must be passed in order to advance to the next stage. Recollection of each word gains a point. Recollection according to order gains a bonus point for each sub-stage. The participant's total score is calculated as the number of points accumulated in all the stages. The range of scores lies between 0 and 50. The internal reliability of the test is alpha $=.78$.

For example, Stage 1: You write on a blackboard with [chalk]; A chicken lays [egg(s)]; A [cow] gives milk; The moon shines at [night].

e) Deciphering pseudo-words (Deutsch, 1992). This tests the participant's phonological-deciphering competence-i.e., his capacity to create a link between a symbol representing a letter (grapheme) and its sound (phoneme). The participant is required to read aloud as precisely and quickly as possible a list of 24 words that do not exist in Hebrew. His speed is measured in seconds and percent accuracy (total of correct answers from all the items).

f) Reading aloud of unvocalized words (Shany, Ben Dror, \& Ravid, 1997; Shany, Zeiger, \& Ravid, 2001). This tests the participant's decipherment aptitude without access to the context. It consists of 50 words. The participant's rate is measured in seconds and percent accuracy (total of correct answers from all the items).

g) Reading aloud from an unvocalized text of 98 words (Shany, Ben Dror, \& Ravid, 1997; Shany, Zeiger, \& Ravid, 2001). This tests the participant's deciphering competence with access to the context. The participant's rate is measured in seconds and percent accuracy (total of correct answers from all the items).

h) Spelling (Shany, Ben Dror, \& Zeiger, 1997; Shany, Zeiger, \& Ravid, 2001). This tests the participant's spelling competence. The test consists of two lists of 20 words each (40 in total) dictated to the participant separately and in a sentence, without a time limit. The first list consists of function words (with, after, on), the second of content words (salary, farmer). It tests percent accuracy (total of correct answers from all the items).

7. Assignments testing English reading and writing abilities, together with assignments assessing the language skills that lie at their base. The majority of the assignments were developed in the neurocognitive lab at the University of Haifa (Kahan-Horwitz, 2003) and implemented at the University's learning-disability-diagnosis clinic. Like the Hebrew test, these assignments are closely studied so that they are given and coded in identical fashion.

a) Vocabulary. This is tested by two assignments that include a list of common words taken from Grade 11 textbooks. The first is semantic identification and requires the participant to choose the most appropriate meaning for a word out of four options. It contains 20 words and tests the percent accuracy of the assignment. The second-semantic inference-requires the participant to adduce a meaning for a given word in a sentence on the basis of the context. It contains 20 words and tests percent accuracy (total of correct answers from all the items).

b) Letter naming - identification of lower and upper case letters. This measures the rate of identification in seconds and percent accuracy (total of correct answers from all the items).

c) Decipherment of pseudo-words. This tests the participant's phonological-decipherment aptitude-i.e., the creation of a link between a symbol representing a letter (grapheme) and its sound (phoneme). The participant has to read aloud as precisely and quickly as possible a list of 20 words that do not exist in English but behave according to English-language rules. The reading rate is measured in seconds and percent accuracy (total of correct answers from all the items).

d) Reading aloud of single words - reading a list of 120 single words on an increasing rate of difficulty. This measures the reading rate in seconds and percent accuracy (total of correct answers from all the items).

e) Reading aloud from the text "Halley's Comet" from the Comprehend series (1995). This tests the participant's decipherment processes, with access to the context. The rate of reading is measured in seconds and percent accuracy (total of correct answers from all the items-110).

f) Spelling. This tests the participant's spelling aptitude via the dictation of two sentences according to age level that contain various syllables, break-down into syllables, morphemes, and unusual words (from the perspective of English orthography). The percent accuracy is examined (total of correct answers from all the items -19). The two sentences are:

1. The two musicians should consider playing a duet together.

2. It is fascinating to examine the geography of different countries.

\subsection{Research Variables}

Due to the multiple variables and tests for examining skills in Hebrew and English, as well as to enable a com- 
parison between the skills in the two languages, it was decided to collect some of the variables into groups of rate and accuracy. Four groups were created for Hebrew and four for English.

- Hebrew skills (independent variables): memory grade, percent accuracy in spelling tests, rate in seconds (letter/number-identification assignments, decipherment of pseudo-words, phonological awareness, reading of a text) and percent accuracy (vocabulary assignments, decipherment of pseudo-words, phonological awareness, morpho-grammatical awareness, reading of single words, reading a text). For the group of variables that constitute the rate of execution the internal reliability level was $a=.78$. For the percent-accuracy variables group it was $\mathrm{a}=.73$.

- English skills (dependent variables): vocabulary percent accuracy, spelling test percent accuracy, rate in seconds (identifying lower and upper case letters, decipherment of pseudo-words, reading single words, reading a text) and percent accuracy (identification of lower and upper case letters assignments, decipherment of pseudo-words, reading single words, reading a text). For the group of variables that constitute the rate of execution the internal reliability level was $a=.89$. For the percent-accuracy variables group it was $\mathrm{a}=.78$.

- Percent accuracy with respect to Hebrew and English (dependent variable). Due to the disparity in the number of items and the accepted range of scores for anxiety tests relating to Hebrew and English, the score of each participant in the anxiety tests was changed into anxiety percent so as to enable a comparison between the two types of anxiety.

- Score in each of the five personality dimensions - neurotic, extrovert, openness to experiences, agreeableness, and conscientiousness (independent variables). Five categories in each personality type were reduced to three -1 = low, 2 = middling, and $3=$ high.

\subsubsection{Procedure}

The first stage was devoted to enlisting the participation of students studying in one of the schools in the north of the country via a personal appeal (on the basis of past acquaintance) on the part of the study's editor and with the help of the Grade advisor. The students assisted in mobilizing additional participants from three other schools in the region via a snowball effect. In parallel, conversations were held with the students' parents to receive their consent for their children's participation in the study while guaranteeing that their personal data would remain confidential and assuring them that the study was not linked to any school framework. A personal session was held with every student at home after school hours in a quiet room without any interruptions. It lasted around one and a half hours. The decision to hold the meeting in the student's home outside school hours derived from the desire to give the students rest time in order to reduce their load and refresh themselves after a day's study. The session was also regarded as friendlier, thereby augmenting the students' response and helping diminish their fear and anxiety - despite the fact that they were given several tests during the meeting. The students and their parents signed a form at the beginning of the session giving their consent to their participation in the research (see Appendix 19). The participants subsequently filled out a personal questionnaire. At the next stage, a battery of tests were administered to test the language skills lying at the base of their L1 reading and writing abilities.

The order of the administration of the tests was as follows. Firstly, assignments examining the linguistic mechanism underlying reading and writing skills and working-memory content, rapid identification, phonological and morpho-grammatical awareness, and vocabulary. Next, reading assignments and decipherment of pseudowords, reading of single words, and reading a text. This was followed by spelling assignments. At the end, of the L1 tests, the participant filled out a questionnaire relating to L1 anxiety. He was then given a break before continuing. During the second stage, assignments examining the language skills lying at the basis of reading and writing in English were administered, in the following order: identifying lower and upper case letters, deciphering pseudo-words, vocabulary, reading single words, reading a text, and sentence dictation. At the end, the participant filled out another questionnaire relating to L2 anxiety. During the final stage, he was engaged in conversation for the purpose of joint completion of a demographic questionnaire and the recording of the participant's impressions regarding the nature of the assignments, their degree of difficulty, and his feelings at the end of the encounter.

\subsubsection{Analysis of the Findings}

In order to examine the relation between L1 skills (percent accuracy, rate, memory grade, and spelling) and L2 
skills (percent accuracy, rate, vocabulary, and spelling), a Pearson correlation analysis was conducted. This was also undertaken in order to investigate the relation between linguistic skills in the two languages and the level of anxiety felt with respect to learning Hebrew and English, as well as the relation between the levels of anxiety themselves and that between each of the personality types and the level of anxiety felt with respect to learning Hebrew and English. A multiple regression analysis was also conducted in order to adduce the competence of the personality types - jointly and separately — to predict anxiety with respect to L1 and L2.

In addition to testing the study's central hypotheses, further analyses were also conducted to examine the gender disparities in all aspects relating to the level of anxiety felt with respect to both languages, personality types, and the performance of various assignments in Hebrew and English - via a t-test. The relation between the demographic variables and language skills in Hebrew and English and the level of anxiety felt with respect to both language was also tested via a Pearson correlation analysis. Likewise, an attempt was made via a staged regression analysis to adduce the predictive power of L2 performance by means of the demographic variables and personality types with and without the involvement of anxiety - in order to examine whether the latter augments the predictive power of English performance via these variables.

\section{Results}

The study set out to examine the relation between basic L1 skills (Hebrew) and L2 skills, as well as that between these skills and the anxiety felt in learning Hebrew and English. A further goal was to examine the relation between personality types and language anxiety. Table 1 presents the mean variables, standard deviations, skill grade, and maximum of each measure.

\subsection{Study Hypotheses}

H1: A relation will exist between L1 (Hebrew) skills and L2 (English) skills

In order to test this hypothesis, a Pearson correlation analysis was conducted, the findings of which are presented in Table 2.

Table 1. Maximum and minimal grade, means, and standard deviations of the study variables $(\mathrm{N}=80)$.

\begin{tabular}{|c|c|c|c|c|c|}
\hline & Variable & Minimum grade & Maximum grade & Mean & SD \\
\hline \multirow{5}{*}{ Hebrew skills } & Percent accuracy & 55.92 & 96.72 & 84.67 & \\
\hline & Rate & 77.29 & 167.55 & 122.38 & 17.72 \\
\hline & Memory grade & 10 & 42 & 27.33 & 7.6 \\
\hline & Spelling & 70 & 100 & 94 & 6.25 \\
\hline & Percent accuracy & 40.97 & 97.95 & 83.45 & 10.15 \\
\hline \multirow{3}{*}{ English skills } & Rate & 49.35 & 150.57 & 81.76 & 19.88 \\
\hline & Vocabulary & 5 & 100 & 72.13 & 23.18 \\
\hline & Spelling & 0 & 94.73 & 60.52 & 16.64 \\
\hline \multirow{5}{*}{ Personality types } & Neuroticism & 1 & 5 & 3.33 & .99 \\
\hline & Extroversion & 1 & 5 & 3.88 & .83 \\
\hline & Openness to experiences & 1 & 5 & 3.29 & .97 \\
\hline & Agreeableness & 1 & 4 & 2.53 & 1.02 \\
\hline & Conscientiousness & 1 & 5 & 2.41 & 1.11 \\
\hline \multirow{3}{*}{ Anxiety level } & Hebrew anxiety level & .05 & .8 & .35 & .15 \\
\hline & & & & & \\
\hline & English anxiety level & .05 & .9 & .39 & .21 \\
\hline
\end{tabular}


Table 2. Relation between Hebrew language skills and English language skills.

\begin{tabular}{cccccc}
\hline Variables & & \multicolumn{3}{c}{ English skills } \\
\hline & & Percent accuracy & Rate & Vocabulary & \multicolumn{2}{c}{ Spelling } \\
Hebrew skills & Percent accuracy & $.78^{* * *}$ & $.44^{* * *}$ & $.58^{* * *}$ & $.62^{* * *}$ \\
& Rate & $.38^{* *}$ & $.59^{* * *}$ & $.26^{*}$ & $.37^{* *}$ \\
& Working memory & $.34^{* *}$ & $.28^{*}$ & $.35^{* *}$ & $.27^{*}$ \\
& Spelling & $.33^{* *}$ & .09 & $.25^{*}$ & $.43^{* * *}$
\end{tabular}

Note: $\mathrm{P}<0.001^{* * *} ; \mathrm{p}<0.01^{* *} ; \mathrm{p}<0.05^{*}$.

The table demonstrates that a significant positive relation obtains between L1 skills and L2 skills (English). In other words, the better grounded a student's Hebrew skills are (e.g., percent accuracy, rate, identification, memory, and spelling) the better are his English skills relating to rate, accuracy, vocabulary, and spelling. These findings confirm the hypothesis. The most striking factor is the strong positive relation between percent accuracy in L1 assignments and all L2 skills. Strong relations also exist between the percent accuracy variables in the two languages and the rate variable.

H2: A negative relation will obtain between L1 (Hebrew) skills and the level of L1 anxiety. Similarly, a negative relation will obtain between L2 (English) skills and the level of L2 anxiety.

The Pearson correlation analysis conducted revealed that a significant negative relation $(\mathrm{p}<0.01)$ obtained between the level of anxiety felt with respect to Hebrew and the basic L1 language skills, content grade in the working-memory test $(\mathrm{r}=-.33)$, percent accuracy $(\mathrm{r}=-.37)$, rate $(\mathrm{r}=-.34)$, and spelling $(\mathrm{r}=-.27)$. In other words, the higher the student's L1 skills, the lower his anxiety with respect to Hebrew. Similarly findings also emerged for L2. The Pearson correlation analysis revealed a significant negative relation $(\mathrm{p}<0.01)$ between the level of anxiety with respect to English and percent accuracy in English $(\mathrm{r}=-.31)$, rate $(\mathrm{r}=-.42)$, vocabulary $(\mathrm{r}$ $=-.46)$, and spelling $(\mathrm{r}=-.29)$. The more skilled the student in L2, the lower was his level of anxiety. The hypothesis was therefore fully confirmed.

H3: A relation will obtain between the levels of $L 1$ and $L 2$ anxiety.

This was tested by a Pearson correlation analysis. The findings indicate that a relatively positive significant relation $(\mathrm{p}<0.05)$ obtained between the two anxieties $(\mathrm{r}=.27)$, confirming the hypothesis. Participants who experienced anxiety with respect to the L1 felt a similar level of anxiety with respect to L2.

H4: A relation will obtain between personality types and the level of $L 1$ anxiety. A relation will similarly exist between personality types and the level of L2 anxiety.

The hypothesis was tested by a Pearson correlation analysis, which indicated that a significant positive relation $(\mathrm{p}<0.000)$ obtained between neuroticism and Hebrew anxiety $(r=.49)$ and English anxiety $(r=.44)$. In other words, the more a person tends towards the neurotic personality type, the greater his language-acquisition level will be. Likewise, a significant negative relation $(\mathrm{p}<0.01)$ obtained between the conscientious personality type and Hebrew anxiety $(\mathrm{r}=.36)$. In other words, the more a person tends towards the conscientious personality type, the less L1 anxiety he will feel. No other significant relations were found to exist between the other personality types and anxiety in relation to the two languages. These findings confirm the hypothesis. At the same time, to date only the discrete relations were examined. In order to test the overall predictive power of the personality types with respect to L1/L2 anxiety a multiple regression test was conducted. The findings of this are presented in Tables 3 and 4.

The table indicates that $43 \%$ of the variables are explained by the personality types, the most significant being the neurotic, open to experiences, agreeable, and conscientious.

The table demonstrates that $48 \%$ of the variables are explained by the personality types, the only significant type being neuroticism.

These findings significantly support the contribution made by the personality types in predicting the level of language anxiety - a factor bearing implications for both diagnosis and treatment. At the same time, the finding that the level of L1 anxiety was predicted by four different personality types while the only one to predict L2 anxiety was neuroticism cannot be ignored. 
Table 3. Regression relating to the prediction of Hebrew anxiety via personality types.

\begin{tabular}{ccccc}
\hline Predictor & R & R Sq. & F & P \\
Overall & .65 & .43 & 11.02 & .00 \\
Predictor & $\mathbf{B}$ & Beta & $\mathbf{t}$ & $\mathbf{P}$ \\
Con. & .30 & & 2.52 & .01 \\
Neuroticism & .09 & .54 & 5.32 & .00 \\
Extroversion & .00 & .00 & .03 & .97 \\
Openness to experiences & -.06 & -.38 & -3.89 & .00 \\
Agreeableness & .03 & .22 & 2.22 & .03 \\
Conscientiousness & -.05 & -.35 & -3.46 & .00 \\
\hline
\end{tabular}

\begin{tabular}{|ccccc}
\hline Table 4. Regression relating to the prediction of English anxiety via personality types. \\
\hline Predictor & $\mathbf{R}$ & $\mathbf{R ~ S q}$ & $\mathbf{F}$ & $\mathbf{P}$ \\
\hline Overall & .48 & .23 & 4.39 & .00 \\
Predictor & $\mathbf{B}$ & Beta & $\mathbf{t}$ & $\mathbf{P}$ \\
Con. & .00 & & -.00 & .99 \\
Neuroticism & .11 & .52 & 4.39 & .00 \\
Extroversion & .01 & .03 & .24 & .81 \\
Openness to experiences & -.02 & -.11 & -.99 & .33 \\
Agreeableness & .01 & .03 & .28 & .78 \\
Conscientiousness & .03 & .14 & 1.18 & .24 \\
\hline
\end{tabular}

\subsection{Additional Analyses}

1. Gender disparities were tested in all aspects relating to the level of L1/L2 anxiety, personality types, and the performance of various assignments in Hebrew and English by a t-test. Table 5 presents the means and standard deviations of boys vs. girls.

Table 5 demonstrates that the Hebrew percent accuracy is higher amongst girls than boys. The English anxiety level is also higher amongst boys. With respect to the personality types, the significant findings were only recorded for neuroticism and agreeableness. Although girls are more prone towards neuroticism than boys, boys tend towards agreeableness more than girls. With respect to L1, the percent accuracy amongst girls was higher than boys only in the spelling tests. With respect to L2 skills, the girls' performance was only significantly higher than that of the boys in the rate tests.

2. The study examined the relation between socio-economic demographics-including the number of visits abroad and the relative overall grade in English and Hebrew/English skills, as well as that between the level of Hebrew/English anxiety. This was tested by a Pearson correlation analysis. The results are presented in Table 6.

The table demonstrates that, with respect to Hebrew language skills, a significant positive but low relation obtains between percent accuracy/memory grade and the relative overall English grade. In other words, the better a student's working memory, as well as his percent accuracy in L1 assignments, the higher his relative overall English grade will be. With respect to English skills, a significant but low positive relation obtained between percent accuracy/vocabulary and the number of times he had been abroad. In other words, the more times he had been abroad the higher his percent accuracy in English assignments was and the richer his vocabulary. A significant positive relation also obtained between assignments assessing rate and the relative overall English grade. In other words, when a student was able to decipher quickly in L2 his relative overall grade was higher. In contrast, no significant relation was found between the socio-demographic variables and the level of Hebrew/English anxiety. 
Table 5. Level of anxiety, personality types, and Hebrew/English skills according to gender.

\begin{tabular}{|c|c|c|c|c|c|}
\hline Variable & Gender & No. of participants & Mean & SD & T-test \\
\hline \multirow[t]{2}{*}{ Hebrew anxiety level } & M & 31 & .3 & .12 & $-2.08^{*}$ \\
\hline & $\mathrm{F}$ & 49 & .38 & .17 & \\
\hline \multirow[t]{2}{*}{ English anxiety level } & M & 31 & .31 & .12 & $-2.56^{*}$ \\
\hline & $\mathrm{F}$ & 49 & .43 & .24 & \\
\hline \multirow[t]{2}{*}{ Neuroticism } & M & 31 & 2.90 & 1.08 & $3.01^{* *}$ \\
\hline & $\mathrm{F}$ & 49 & 3.55 & .84 & \\
\hline \multirow[t]{2}{*}{ Extroversion } & M & 31 & 3.81 & .98 & -.58 \\
\hline & $\mathrm{F}$ & 49 & 3.92 & .73 & \\
\hline \multirow[t]{2}{*}{ Openness to experiences } & M & 31 & 3.06 & 1.09 & -1.66 \\
\hline & $\mathrm{F}$ & 49 & 3.43 & .87 & \\
\hline \multirow[t]{2}{*}{ Agreeableness } & M & 31 & 2.90 & .94 & $2.75^{* *}$ \\
\hline & $\mathrm{F}$ & 49 & 2.29 & 1.00 & \\
\hline \multirow[t]{2}{*}{ Conscientiousness } & M & 31 & 2.61 & 1.38 & 1.29 \\
\hline & $\mathrm{F}$ & 49 & 2.29 & .89 & \\
\hline \multirow[t]{2}{*}{ English percent accuracy } & M & 31 & 86.18 & 11.85 & 1.94 \\
\hline & $\mathrm{F}$ & 49 & 81.73 & 8.60 & \\
\hline \multirow[t]{2}{*}{ English rate } & M & 31 & 91.25 & 23.19 & $3.65^{* * *}$ \\
\hline & $\mathrm{F}$ & 49 & 75.75 & 14.82 & \\
\hline \multirow[t]{2}{*}{ English vocabulary } & M & 31 & 75.82 & 27.40 & 1.14 \\
\hline & $\mathrm{F}$ & 49 & 69.8 & 20.00 & \\
\hline \multirow[t]{2}{*}{ English spelling } & M & 31 & 64.00 & 20.21 & 1.5 \\
\hline & $\mathrm{F}$ & 49 & 58.32 & 13.71 & \\
\hline \multirow[t]{2}{*}{ Hebrew percent accuracy } & M & 31 & 84.73 & 9.51 & .05 \\
\hline & $\mathrm{F}$ & 49 & 84.63 & 7.69 & \\
\hline \multirow[t]{2}{*}{ Hebrew rate } & M & 31 & 126.31 & 19.34 & 1.60 \\
\hline & $\mathrm{F}$ & 49 & 119.89 & 16.32 & \\
\hline \multirow[t]{2}{*}{ Hebrew memory grade } & M & 31 & 28.94 & 9.22 & 1.52 \\
\hline & $\mathrm{F}$ & 49 & 26.31 & 6.26 & \\
\hline \multirow[t]{2}{*}{ Hebrew spelling } & M & 31 & 92.18 & 8.06 & $-2.12^{*}$ \\
\hline & $\mathrm{F}$ & 49 & 95.15 & 4.49 & \\
\hline
\end{tabular}

Note: $\mathrm{P}<0.001^{* * *} ; \mathrm{p}<0.01^{* *} ; \mathrm{p}<0.05^{*}$.

3. A further analysis was designed to predict English performance by means of the personality types and demographic variables with and without the involvement of anxiety. Tables 7-10 present the staged regression for English language skills.

The table demonstrates that $29 \%$ of the performance variance is explained by the personality types (the most significant of these being neuroticism) and demographic variables (the most significant of these being the number of visits abroad and English grade) without the involvement of anxiety. In contrast, $39 \%$ of the variance is ex- 
Table 6. Relation between demographic variables and Hebrew/English language skills and anxiety level with respect to both languages.

\begin{tabular}{ccc}
\hline Variable & Number of visits abroad & Overall relative English grade \\
\hline Percent accuracy & .19 & $.28^{*}$ \\
Rate & -.07 & .08 \\
Memory grade & .05 & $.22^{*}$ \\
Spelling & -.01 & .02 \\
Percent accuracy & $.26^{*}$ & $.23^{*}$ \\
Rate & .14 & $.29^{* *}$ \\
Vocabulary & $.29^{*}$ & .17 \\
Spelling & .19 & .20 \\
Hebrew anxiety level & .13 & -.12 \\
English anxiety level & -.05 & -.14 \\
\hline
\end{tabular}

Note: $\mathrm{P}<0.05^{*} ; \mathrm{p}<0.01^{* *} ; \mathrm{p}<0.001^{* * *}$.

Table 7. Staged regression for the prediction of English accuracy with and without the involvement of anxiety.

\begin{tabular}{|c|c|c|c|c|c|}
\hline Stage & Predictor & $\mathbf{R}$ & R Sq. & $\mathbf{F}$ & $\mathbf{P}$ \\
\hline 1 & General & .54 & .29 & 3.69 & .00 \\
\hline 2 & General & .63 & .39 & 4.47 & .00 \\
\hline Stage & Predictor & B & Beta & $\mathbf{t}$ & $\mathbf{P}$ \\
\hline \multirow[t]{9}{*}{1} & Con. & 95.76 & & 10.09 & .00 \\
\hline & Neuroticism & -2.93 & -.28 & -2.34 & .02 \\
\hline & Extroversion & -.73 & -.06 & -.56 & .58 \\
\hline & Openness to experiences & 1.54 & .15 & 1.29 & .2 \\
\hline & Agreeableness & 1.01 & .10 & .88 & .38 \\
\hline & Conscientiousness & -1.73 & -.19 & -1.61 & .11 \\
\hline & Gender & -3.42 & -.17 & -1.48 & .14 \\
\hline & Number of visits abroad & .55 & .25 & 2.45 & .02 \\
\hline & Relative overall English grade & 1.09 & .21 & 2.04 & .05 \\
\hline \multirow[t]{11}{*}{2} & Con. & 101.87 & -.02 & 11.14 & .00 \\
\hline & Neuroticism & -.24 & & -.17 & .87 \\
\hline & Extroversion & .79 & -.07 & -.64 & .52 \\
\hline & Openness to experiences & -.52 & -.05 & -.40 & .69 \\
\hline & Agreeableness & 2.32 & .23 & 2.01 & .05 \\
\hline & Conscientiousness & -3.0 & -.33 & -2.71 & .01 \\
\hline & Gender & -1.54 & -.07 & -.68 & .50 \\
\hline & Number of visits abroad & .65 & .30 & 3.03 & .00 \\
\hline & Relative overall English grade & .74 & .14 & 1.43 & .16 \\
\hline & Level of Hebrew anxiety & -27.50 & -.42 & -3.19 & .00 \\
\hline & Level of English anxiety & -5.46 & -.11 & -1.01 & .32 \\
\hline
\end{tabular}


Table 8. Staged regression for the prediction of rate of decipherment in English with and without the involvement of anxiety.

\begin{tabular}{|c|c|c|c|c|c|}
\hline Stage & Predictor & $\mathbf{R}$ & R Sq. & $\mathbf{F}$ & $\mathbf{P}$ \\
\hline 1 & General & .59 & .35 & 4.69 & .00 \\
\hline 2 & General & .63 & .40 & 4.58 & .00 \\
\hline Stage & Predictor & B & Beta & $\mathbf{t}$ & $\mathbf{P}$ \\
\hline \multirow[t]{9}{*}{1} & Con. & 123.66 & & 6.91 & .00 \\
\hline & Neuroticism & -5.82 & -.29 & -2.47 & .02 \\
\hline & Extroversion & -1.16 & -.05 & -.47 & .64 \\
\hline & Openness to experiences & 1.27 & .06 & .56 & .58 \\
\hline & Agreeableness & 1.32 & .07 & .61 & .54 \\
\hline & Conscientiousness & -3.28 & -.18 & -1.61 & .11 \\
\hline & Gender & -12.72 & -.31 & -2.29 & .01 \\
\hline & Number of visits abroad & .66 & .15 & 1.55 & .13 \\
\hline & Relative overall English grade & 2.61 & .25 & 2.95 & .01 \\
\hline \multirow[t]{11}{*}{2} & Con. & 128.97 & & 7.22 & .00 \\
\hline & Neuroticism & -1.89 & -.09 & -.67 & .51 \\
\hline & Extroversion & -1.24 & -.05 & -.51 & .61 \\
\hline & Openness to experiences & -1.16 & -.06 & -.47 & .64 \\
\hline & Agreeableness & 2.82 & .14 & 1.25 & .21 \\
\hline & Conscientiousness & -4.16 & -.23 & -1.92 & .06 \\
\hline & Gender & -9.66 & -.24 & -2.19 & .03 \\
\hline & Number of visits abroad & .73 & .17 & 1.74 & .09 \\
\hline & Relative overall English grade & 2.11 & .21 & 2.09 & .04 \\
\hline & Hebrew anxiety level & -25.53 & -.20 & 1.52 & .13 \\
\hline & English anxiety level & -20.21 & -.21 & -1.92 & .06 \\
\hline
\end{tabular}

plained by personality types (the most significant of these being agreeableness and conscientiousness) and demographic variables (the most significant of these being the number of visits abroad) when anxiety mediates. In other words, the involvement of the anxiety variable significantly improves prediction of the percent accuracy in the various L2 assignments.

The table demonstrates that $35 \%$ of the performance variance is explained by the personality types (the most significant of these being neuroticism) and demographic variables (the most significant of these being gender and English grade) without the involvement of anxiety. In contrast, $40 \%$ of the variance is explained by the personality types (none being more significant than the others) and demographic variables (the most significant of these being gender and relative overall grade) when anxiety mediates.

The table demonstrates that $32 \%$ of the performance variance is explained by the personality traits (the most significant of these being neuroticism, openness to experiences, and conscientiousness) and demographic variables (the most significant of these being the number of visits abroad) without the involvement of anxiety. In contrast, $41 \%$ of the variance was explained by personality types (the most significant being conscientiousness) and demographic variables (the most significant of these being the number of visits abroad) when anxiety mediates. In this case, a significant increase in the ability to predict performance due to the involvement of anxiety was evident. 
Table 9. Regression according to stages for the prediction of English vocabulary with and without the involvement of anxiety.

\begin{tabular}{|c|c|c|c|c|c|}
\hline Stage & Predictor & $\mathbf{R}$ & R Sq. & $\mathbf{F}$ & $\mathbf{P}$ \\
\hline 1 & General & .57 & .32 & 4.22 & .00 \\
\hline \multirow[t]{2}{*}{2} & General & .64 & .41 & 4.78 & .00 \\
\hline & & B & Beta & $\mathbf{t}$ & $\mathbf{P}$ \\
\hline \multirow[t]{9}{*}{1} & Con. & 107.82 & & 5.08 & .00 \\
\hline & Neuroticism & -8.08 & -.34 & -2.89 & .01 \\
\hline & Extroversion & -2.95 & -.11 & -1.01 & .32 \\
\hline & Openness to experiences & 6.62 & 28. & 2.48 & .02 \\
\hline & Agreeableness & -1.07 & -0.5 & -.41 & .68 \\
\hline & Conscientiousness & -4.87 & -.23 & -2.01 & .05 \\
\hline & Gender & -6.14 & -.13 & -1.19 & .24 \\
\hline & Number of visits abroad & 1.20 & .24 & 2.39 & .02 \\
\hline & Relative overall English grade & 2.02 & .17 & 1.69 & .10 \\
\hline \multirow[t]{11}{*}{2} & Con. & 112.29 & & 5.45 & .00 \\
\hline & Neuroticism & -2.77 & -.12 & -.85 & .40 \\
\hline & Extroversion & -3.05 & -.11 & -1.10 & .28 \\
\hline & Openness to experiences & 3.72 & -.16 & 401.29 & .20 \\
\hline & Agreeableness & .69 & .03 & .26 & .79 \\
\hline & Conscientiousness & -5.42 & -.26 & -2.17 & .03 \\
\hline & Gender & -1.79 & -.04 & -.35 & .73 \\
\hline & Number of visits abroad & 1.24 & .25 & 2.58 & .01 \\
\hline & Relative overall English grade & 1.35 & .11 & 1.16 & .25 \\
\hline & Hebrew anxiety level & -25.03 & -.17 & -1.29 & .20 \\
\hline & English anxiety level & -35.27 & -.32 & -2.90 & .01 \\
\hline
\end{tabular}

The table demonstrates that $20 \%$ of the performance variance is explained by the personality types (none being more significant than another) and demographic variables (none being more significant than another) without the involvement of anxiety. In contrast, $27 \%$ of the variance is explained by the personality types (none being more significant than another) and demographic variables (the most significant being the number of visits abroad) when anxiety mediates.

In summary, the trend that emerges from the tables points to the significant degree to which anxiety augments the predictive power of English performance via the personality types and demographic variables. Analysis of the most prominent personality type indicates that neuroticism predicts English performance. Similarly, with respect to the demographic variables, the number of visits abroad constituted the most significant predictor of L2 performance. At the same time, without the involvement of anxiety its predictive power decreases. It must also be noted that the level of significance rises when anxiety is involved.

\section{Discussion}

The present study sought to integrate two theoretical approaches by examining the relation between L1/L2 language skills and anxiety with respect to the two languages, together with the relation between language anxiety 
Table 10. Staged regression for the prediction of English spelling competence with and without the involvement of anxiety.

\begin{tabular}{|c|c|c|c|c|c|}
\hline Stage & Predictor & $\mathbf{R}$ & R Sq. & $\mathbf{F}$ & $\mathbf{P}$ \\
\hline 1 & General & .44 & .20 & 2.17 & .04 \\
\hline 2 & General & .52 & .27 & 2.58 & .01 \\
\hline Stage & Predictor & B & Beta & $\mathbf{t}$ & $\mathbf{P}$ \\
\hline \multirow[t]{9}{*}{1} & Con. & 62.52 & & 3.77 & .00 \\
\hline & Neuroticism & -4.05 & -.24 & -1.85 & .70 \\
\hline & Extroversion & .62 & .03 & .27 & .79 \\
\hline & Openness to experiences & 2.29 & .13 & 1.10 & .28 \\
\hline & Agreeableness & .77 & .05 & .38 & .71 \\
\hline & Conscientiousness & 1.01 & .07 & .54 & .59 \\
\hline & Gender & -3.78 & -.11 & -.94 & .35 \\
\hline & Number of visits abroad & .77 & .21 & 1.95 & .06 \\
\hline & Relative overall English grade & 1.61 & .19 & 1.72 & .09 \\
\hline \multirow[t]{11}{*}{2} & Con. & 70.79 & & 4.31 & .00 \\
\hline & Neuroticism & -.07 & -.00 & -.03 & .98 \\
\hline & Extroversion & .53 & .03 & .24 & .81 \\
\hline & Openness to experiences & -.63 & -.04 & -.28 & .78 \\
\hline & Agreeableness & 2.61 & .16 & 1.26 & .21 \\
\hline & Conscientiousness & -.67 & -.05 & -.34 & .74 \\
\hline & Gender & -.93 & -.03 & -.23 & .82 \\
\hline & Number of visits abroad & .90 & .25 & 2.33 & .02 \\
\hline & Relative overall English grade & 1.09 & .13 & 1.18 & .24 \\
\hline & Hebrew anxiety level & -37.72 & -.35 & -2.44 & .02 \\
\hline & English anxiety level & -10.60 & -.13 & -1.90 & .28 \\
\hline
\end{tabular}

Personality Questionnaire Based on the Five Factors Model

and personality types.

Our first hypothesis was that a positive relation would obtain between L1 language skills and L2 skills. This hypothesis was confirmed, significant positive relations existing between all the Hebrew and English language skills. Strong relations also obtained between the assignments assessing L2 percent accuracy and rate. These findings support Cummins' $(1979,1989)$ theory regarding the transfer of skills from one language to another, according to which a relation exists between a student's cognitive and academic abilities - as well as his L1 linguistic aptitude - and his acquisition of a new language. In other words, the skills one from language are transferred to the other, the person with more L1 practice thus being better at transferring these skills to the other language. They also support Ganschow, Sparks et al.'s thesis (Ganschow et al., 1992; Sparks et al., 1992; Ganschow, Sparks, \& Javorsky, 1998; Sparks, Ganschow, \& Javorsky, 2000) that phonological, orthographical, grammatical, and semantic L1 skills form the basis for learning L2. These authors found that students who find learning L2 difficult have low-level learning disabilities in L1 in contrast to L2 high achievers.

Examination of the predictors of L2 acquisition indicated a phonetic coding, grammatical sensitivity, language-learning and memorization aptitude (Ganschow et al., 1994). Service (1992; cited in Ganschow \& Sparks, 1996) has shown that phonological and orthographic tasks — such repeating pseudo-words, and the ability to 
compare semantic structures_-predicts English acquisition amongst Finnish students. She thus contends that the ability to represent unfamiliar phonological material in the working memory-which is involved in processing and storing information - forms the basis for acquiring new vocabulary and developing reading, understanding, and speech abilities during the learning of L2. Geva \& Siegel's (2000) study similarly demonstrated a strong link between reading pseudo-words, identifying words, working memory, and syntactical awareness in Hebrew as L1 and these skills in L2 (English). Other studies have pointed to L1 skills such as phonology, morphology, syntax, genre-knowledge, and strategies for adducing meaning as serving as instruments for acquiring L2 skills (Durgunoglu, 2002; Lopez \& Greenfield, 2004).

The second hypothesis predicted a negative relation between L1 skills and the level of anxiety felt with respect to L2, as well as a negative relation between L2 skills and the level of anxiety felt with respect to L2. This hypothesis was also confirmed, strong relations demonstrating themselves to exist between all the linguistic skills in both languages and the level of anxiety felt with respect to the language. In other words, students with good language skills in both Hebrew and English exhibited a low level of anxiety with respect to both.

These results constitute both a new finding and a significant expansion of the results of previous studies in the field (Ganschow \& Sparks, 1996; Ganschow et al., 1994; Ganschow, Sparks, \& Javorsky, 1998; Sparks \& Ganschow, 1993; Sparks et al., 1992; Sparks, Ganschow, \& Javorsky, 1998), which focused on the interaction between an individual's L1 language skills and the level of L2 anxiety. The findings of these studies pointed to variances in the performance of tasks testing spoken language (listening and conversation), phonological processing, orthographic knowledge, and L2 learning aptitude between students exhibiting high and low levels of anxiety. In other words, more anxious students displayed lower L1 language skills, lower L2 learning aptitude, and thus a lower achievement level in L2 acquisition. The findings of the present study also corroborate and supplement the findings of Abu-Rabia (2004), according to which a negative relation obtains between L2 spelling competence/reading comprehension and the level of anxiety with respect to L2.

The innovation of the present study lies in its reference to the presence of anxiety relating to L1 tasks - a field that has yet to be studied to date. As noted above, a significant negative relation obtained between the level of the skills of the participants tested in Hebrew and the level of L1 anxiety. This circumstance can be explained via the literature regarding learning disabilities. As noted above, Ganschow \& Sparks (1993, 1996) have demonstrated that students with learning disabilities and borderline cases exhibit similar difficulties in L1 language coding. Numerous studies have shown that students with learning disabilities find it difficult to meet academic requirements. Thus experiencing high levels of anxiety together with low control focus and disparities between their abilities and achievements, they are inclined to be self-critical, doubt their aptitude, and have lower a self-esteem level than students who do not suffer from learning disabilities. Students with learning-disabilities have a lower achievement level, also assessing their intellectual capacities at a lower level (Heiman \& Precel, 2003; Margalit \& Raviv, 1984; Sobornie, 1994). Ryan (1994) posits that anxiety is the commonest emotional symptom amongst adults with reading disabilities - a product of the frustration and confusion they experienced at school. People with reading disabilities not being able to anticipate failure, the effort to cope with a new situation induces anxiety in them. In light of these facts, participants with L1 language skill difficulties would appear to be apprehensive about undertaking the various assignments in Hebrew due to unpleasant past experience, thereby leading to an increased sense of anxiety.

The negative relation between L2 skills and L2 anxiety may be explained due to the strong relation between the language skills in both languages. As noted above, people with learning disabilities or borderline cases find difficulty with phonological processing, exemplified in an inability to pronounce syllables in L2 correctly or read aloud without making mistakes. They also suffer from short-term and working-memory difficulties, expressed via problems with vocabulary retention or the understanding of grammatical rules that are unaccompanied by connective practice. Many students with learning disabilities are also easily distracted during lessons or exams, thus finding it difficult to complete assignments, answer questions as required, define learning goals, or exercise control techniques. In consequence, they experience anxiety due to their awareness of their difficulties, comparing their aptitude with those of their classroom peers. Their anxiety also derives from a lack of appropriate compensatory strategies at their disposal in other subjects or from a lack of comprehension of some of the classroom activities (Arries, 1999).

Our third hypothesis anticipated a relation between the level of L1 and L2 anxiety. This hypothesis was confirmed, the findings indicating that participants who experienced L1 anxiety also felt a similar level of anxiety with respect to English. The relation between the two forms of anxiety is to be expected in light of the strong re- 
lationship between language skills in the two languages, as well as the relationship between Hebrew/English skills and the level of Hebrew and English anxiety. Participants who exhibited difficulty in basic skills, and thus also anxiety, while undertaking L1 assignments were not in control of their L2 language skills - an anxiety-inducing circumstance. Despite the fact that this field has yet to be investigated, a similarity exists between these findings and Yamashita's (2004) study, which examined the relation between the grasp of reading in L1 and L2 while relating to the product of reading (the level of reading comprehension and the reading process (strategies operated by the reader). This study indicated that a transfer exists between the grasp of reading in L1 and L2. This transfer also occurs on the cognitive (reading and strategic skills) and emotional planes (ideas and approaches). At the same time, L2 competency is not identified as constituting an important factor in the transfer of attitudes towards reading - a finding inconsistent with the results of the present study. It was found that the cognitive and emotional factor relate differently to L1 and L2. In other words, the transfer of the emotional factor in reading is influenced to a lesser degree than L2 competence, the student who exhibits a positive attitude to L1 reading thus also being likely to display a positive attitude towards L2 reading - even if his achievements do not lie on a high level. The present study points to a relation between L2 skills and the level of anxiety linked to them.

Our fourth hypothesis was that a relation would obtain between personality types and the level of L1/L2 anxiety. This hypothesis was confirmed, a significant positive relation demonstrating itself between neuroticism and Hebrew and English anxiety. A significant negative link also existed between conscientiousness and L1 (but not L2) anxiety. The attempt to predict the level of Hebrew anxiety via personality types showed that personality explains $43 \%$ of the variance, while with respect to English anxiety it explains $48 \%$ of the variance. This finding indicates the contribution personality types make to predicting anxiety, allocating them a significant place alongside language skills. The present study expands the findings of earlier research (MacIntyre \& Charos, 1996), which highlighted the prediction of L2 communication competency by means of personality types while endeavoring to reduce anxiety levels. This study demonstrated that extroverts and those with low levels of neuroticism feel less anxiety and are more involved in social interactions in L2.

The present study was marked by the fact that the level of L1 anxiety was predicted by four different personality types (neuroticism, openness to experiences, agreeableness, and conscientiousness) while with respect to L2 only one type (neuroticism) contributed to anxiety. For L1 anxiety, heterogeneity among the personality types thus appears to be high. In other words, those types that are characterized by a high level of emotional stability, openness to outside experiences, agreeableness, acceptance, and a high degree of organization feel less anxiety when undertaking various L1 tasks. In distinction, neuroticism plays a significant role with respect to L2 anxiety, the remainder of the personality types neither significantly heightening or reducing the level of anxiety.

The present study also conducted additional analyses, including an examination of gender differences in relation to all aspects of anxiety, personality types, and language skills in both languages. It indicates, first of all, that the level of both Hebrew and English anxiety is higher amongst girls. This finding corresponds to the results of Abu-Rabia's (2004) study, according to which the gender variable constituted the most significant predictor of anxiety, girls exhibiting higher levels of anxiety than boys. The present study expands the scope of the previous one by showing that girls were more prone to neuroticism than boys, more boys falling into the agreeableness category than girls.

This trend strengthens the dependence between neuroticism and anxiety with respect to Hebrew and English language skills, being anticipated only for Hebrew spelling and English rate rather that for all the components lying at the base of language abilities. The rate of English decipherment was higher amongst girls than boys, as also percent accuracy in Hebrew spelling. This finding is inconsistent with Abu-Rabia's (2004) previous study, which demonstrated gender disparities in favor of the boys in all of the language tasks. At the same time, it supports other studies (Ehrman \& Oxford, 1995; Onwuegbuzie, Bailey, \& Daley, 2000), which indicate that L2 performance amongst boys was lower than amongst girls. It was suggested in these studies that females are more inclined to employ meta-cognitive (planning, assessment, organization), learning, emotional, and social strategies than males. Their listening skills are likewise better, aiding them in language acquisition.

A further analysis pointed to a significant but low positive relation between percent accuracy/working-memory grade in Hebrew and relative overall English grade. Previous studies have also indicated a relation between memory and L1 achievements. This finding is explained by the fact that working/short-time memory - both of which are involved in process and storing information - play a significant role in linguistic processing (including vocabulary acquisition, speech production, reading development, and language comprehension) (Ganschow \& Sparks, 1996). With respect to percent accuracy, this finding reinforces the relation between L1 and L2 skills. 
With respect to English skills, a significant positive but low relation obtained between percent accuracy/vocabulary and the number of visits abroad. In other words, the more times a student had been abroad the higher his English percent accuracy and the richer his vocabulary. This can be explained by the fact that English is used in many countries, thereby increasing the likelihood that students going out of the country would use it more frequently and in various situations, thereby increasing their English competence and encouraging a more positive attitude towards the language. A significant positive relation was also found to obtain between assignments testing rate and relative overall English grade. In other words, when a student exhibited a rapid rate of L2 decipherment his relative overall grade was also higher.

Another analysis conducted in this study was designed to predict English performance via personality types and demographic variables with and without the involvement of anxiety. The results indicate that the involvement of anxiety significantly increased the predictive power of English performance in its various forms by means of personality types and demographic variables. With respect to the former, a striking finding demonstrates that neuroticism predicts English performance. Similarly, with respect to the demographic variables, the number of visits abroad constituted the most significant factor in predicting L2 linguistic performance. These findings shed light on the factors predicting L2 performance. In addition to L2 linguistic abilities, the student's personality type and demographic background also play a central role - it also being important to recognize the significant contribution anxiety makes to the process of language acquisition.

In summary, the findings of the present study expand the existing scope in the current literature and highlight the need to integrate two central theories that complement one another and together provide a better explanation of the complex field. This study demonstrates that the more well grounded a student's L1 skills are, the more confident he will feel in his abilities and less anxiety he will experience while undertaking L1 assignments. Furthermore, adequate L1 language performance enables an effective transfer of skills to L2, thereby facilitating the acquisition of another language and reducing the level of anxiety attendant upon this task. At the same time, together with the great contribution made by language skills, the central role played by personality types in predicting the level of L1 anxiety and in the process of language acquisition cannot be ignored. Similarly, the significant function of language anxiety must be recognized. On the one hand, this is the product of L1 skills. On the other hand, it also predicts future L2 performance. In light of these factors, examination of the field of L2 acquisition must be undertaken from a broad perspective, paying attention to the complex of linguistic, personality, demographic, and language components that comprise the process.

This study raises awareness of the need for early detection of students at risk of experiencing anxiety and thus learning failure. Intervention programs to reduce anxiety must be developed that adduce the student's personality type in order to turn his learning experience into a more positive endeavor. It also stresses the importance of grounding L1 language skills prior to and during L2 acquisition in order to facilitate the transfer of language abilities from L1 to L2 and help reduce language anxiety.

\section{References}

Abu-Rabia, S. (2004). Teachers' Role, Learners' Gender Difference and FL Anxiety among Seventh-Grade Students Studying English as FL. Educational Psychology, 24, 711-729. http://dx.doi.org/10.1080/0144341042000263006

Argaman, O., \& Abu-Rabia, S. (2002). The Influence of Language Anxiety on English Reading and Writing Task among Native Hebrew Speakers. Language, Culture and Curriculum, 15, 143-160.

http://dx.doi.org/10.1080/07908310208666640

Arries, J. F. (1999). Learning Disabilities and Foreign Languages: A Curriculum Approach to the Design of Inclusive Courses. Modern Language Journal, 83, 98-110. http://dx.doi.org/10.1111/0026-7902.00008

Bailey, P., Onwuegbuzie, A. J., \& Daley, C. E. (2000). Study Habits and Anxiety about Learning Foreign Languages. Perceptual and Motor Skills, 90, 1150-1156. http://dx.doi.org/10.2466/pms.2000.90.3c.1151

Casado, M. A., \& Dereshiwsky, M. I. (2001). Foreign Language Anxiety of University Students. College Student Journal, 35, 539-551.

Comprehend (1995). Halley's Comet. New Delhi: Learners Press.

Costa, P. T., \& McCrae, R. R. (1992). Revised NEO Personality Inventory (NEO-PIR) and NEO Five-Factor Inventory Professional Manual. Odessa, TX: Psychological Assessment Resources.

Cummins, J. (1979). Linguistic Interdependence and the Educational Development of Bilingual Children. Review of Educational Research, 49, 222-251. http://dx.doi.org/10.3102/00346543049002222 
Cummins, J. (1989). A Theoretical Framework for Bilingual Special Education. Exceptional Children, 56, 111-119.

Deutsch, A. (1992). Activation of Attention Mechanisms in the Syntactic Domain by Severely Reading Disabled Children. Ph.D. Dissertation, Jerusalem: Hebrew University of Jerusalem.

Durgunoglu, A. Y. (2002). Cross-Linguistic Transfer in Literacy Development and Implications for Language Learners. Annals of Dyslexia, 52, 189-204. http://dx.doi.org/10.1007/s11881-002-0012-y

Ehrman, M. E., \& Oxford, R. L. (1995). Cognition Plus: Correlates of Language Learning Success. Modern Language Journal, 79, 67-89. http://dx.doi.org/10.1111/j.1540-4781.1995.tb05417.x

Ganschow, L., \& Sparks, R. (1996). Anxiety about Foreign Language Learning among High School Women. Modern Language Journal, 80, 199-212. http://dx.doi.org/10.1111/j.1540-4781.1996.tb01160.x

Ganschow, L., Sparks, R., \& Javorsky, J. (1998). Foreign Language Learning Difficulties: An Historical Perspective. Journal of Learning Disabilities, 31, 248-258. http://dx.doi.org/10.1177/002221949803100304

Ganschow, L., Sparks, R., Anderson, R., Javorsky, J., Skinner, S., \& Patton, J. (1994). Differences in Language Performance among High-, Average-, and Low-Anxious College Foreign Language Learners. Modern Language Journal, 78, 41-55. http://dx.doi.org/10.1111/j.1540-4781.1994.tb02013.x

Gardner, R. C., Lalonde, R. N., Moorcroft, R., \& Evers, F. T. (1987). Second Language Attrition: The Role of Motivation and Use. Journal of Language and Social Psychology, 6, 29-47. http://dx.doi.org/10.1177/0261927X8700600102

Geva, E., \& Siegel, L. (2000). Orthographic and Cognitive Factors in the Concurrent Development of Basic Skills in Two Languages. Reading and Writing: An Interdisciplinary Journal, 12, 1-30. http://dx.doi.org/10.1023/A:1008017710115

Gregersen, T., \& Horwitz, E. K. (2002). Language Learning and Perfectionism: Anxious and Non-Anxious Learners' Reactions to Their Own Oral Performance. Modern Language Journal, 86, 562-570. http://dx.doi.org/10.1111/1540-4781.00161

Heiman, T., \& Precel, K. (2003). Students with Learning Disabilities in Higher Education: Academic Strategies Profile. Journal of Learning Disabilities, 36, 248-258. http://dx.doi.org/10.1177/002221940303600304

Horwitz, E. K. (1991). Preliminary Evidence for the Reliability and Validity of a Foreign Language Anxiety Scale. In E. K. Horwitz, \& D. J. Young (Eds.), Language Anxiety: From Theory and Research to Classroom Implications (pp. 37-39). Englewood Cliffs, NJ: Prentice Hall.

Horwitz, E. K. (1995). Student Affective Reactions and the Teaching and Learning of Foreign Languages. International Journal of Educational Research, 23, 573-579. http://dx.doi.org/10.1016/0883-0355(96)80437-X

Horwitz, E. K., Horwitz, M., \& Cope, J. (1986). Foreign Language Classroom Anxiety. Modern Language Journal, 70, 125132. http://dx.doi.org/10.1111/j.1540-4781.1986.tb05256.x

Horwitz, E. K. \& Young, D. J. (1991). Language Anxiety: From Theory and Research to Classroom Implications. Englewood Cliffs, NJ: Prentice Hall.

Kahan-Horwitz, G. (2003). English as a Foreign Language: An Informal Diagnosis. Tivon: Oranim (Hebrew).

Levine, S. G. (2003). Student and Instructor Beliefs and Attitudes about Target Language Use, First Language Use, and Anxiety: Report of a Questionnaire Study. Modern Language Journal, 87, 343-364.

http://dx.doi.org/10.1111/1540-4781.00194

Lieblich, A., Ben Shahar-Segev, N., \& Ninio, A. (1976). WISC-R (Hebrew translation). Jerusalem: Ministry of Education and Culture.

Lopez, L. M., \& Greenfield, D. B. (2004). The Cross-Language Transfer of Phonological Skills of Hispanic Headstart Children. Bilingual Research Journal, 28, 1-18. http://dx.doi.org/10.1080/15235882.2004.10162609

MacIntyre, P. D., \& Charos, C. (1996). Personality, Attitudes, and Affect as Predictors of Second Language Communication. Journal of Language and Social Psychology, 15, 3-26. http://dx.doi.org/10.1177/0261927X960151001

MacIntyre, P. D., \& Gardner, R. C. (1994). The Subtle Effects of Language Anxiety on Cognitive Processing in the Second Language. Language Learning, 44, 283-305. http://dx.doi.org/10.1111/j.1467-1770.1994.tb01103.x

Madsen, H. S., Brown, B. L., \& Jones, R. L. (1991). Evaluating Students' Attitudes toward Second Language Tests. In E. K. Horwitz, \& D. J. Young (Eds.), Language Anxiety: From Theory and Research to Classroom Implications (pp. 65-86). Englewood Cliffs, NJ: Prentice Hall.

Margalit, M., \& Raviv, A. (1984). LDs' Expressions of Anxiety in Terms of Minor Somatic Complaints. Journal of Learning Disabilities, 17, 226-228. http://dx.doi.org/10.1177/002221948401700408

Montague, I. (1993). NEO PI-R Questionnaire. Ramot: Tel Aviv University.

Ohata, K. (2005). Potential Sources of Anxiety for Japanese Learners of English: Preliminary Case Interviews with Five Japanese College Students in the US. Teaching English as a Second or Foreign Language, 9, 1-21.

Onwuegbuzie, A. J., Bailey, P., \& Daley, C. E. (1999a). Relationships between Anxiety and Achievement at Three Stages of 
Learning a Foreign Language. Perceptual and Motor Skills, 88, 1085-1093.

http://dx.doi.org/10.2466/pms.1999.88.3c.1085

Onwuegbuzie, A. J., Bailey, P., \& Daley, C. (1999b). Factors Associated with Foreign Language Anxiety. Applied Psycholinguistics, 20, 217-239. http://dx.doi.org/10.1017/S0142716499002039

Onwuegbuzie, A., Bailey, P., \& Daley, C. (2000). Cognitive, Affective, Personality and Demographic Predictors of Foreign Language Achievement. Journal of Educational Research, 94, 3-15. http://dx.doi.org/10.1080/00220670009598738

Phillips, E. A. (1992). The Effects of Language Anxiety on Students' Oral Performance and Attitude. Modern Language Journal, 76, 14-26. http://dx.doi.org/10.1111/j.1540-4781.1992.tb02573.x

Price, M. L. (1991). The Subjective Experience of Foreign Language Anxiety: Interview with Highly Anxious Students. In E. K. Horwitz, \& D. J. Young (Eds.), Language Anxiety: From Theory and Research to Classroom Implications (pp. 101-108). Englewood Cliffs, NJ: Prentice Hall.

Rodriguez, M., \& Abreu, O. (2003). The Stability of General Foreign Language Classroom Anxiety across English and French. Modern Language Journal, 87, 365-374. http://dx.doi.org/10.1111/1540-4781.00195

Ryan, M. (1994). Social and Emotional Problems Related to Dyslexia. Perspectives: Orton Dyslexia Society, 20, 1-4.

Sobornie, E. J. (1994). Social-Affective Characteristics in Early Adolescents Identified as Learning Disabled and Non-Disabled. Learning Disability Quarterly, 17, 268-279. http://dx.doi.org/10.2307/1511124

Saito, Y., Garza, T. J., \& Horwitz, E. K. (1999). Foreign Language Reading Anxiety. Modern Language Journal, 83, 202218. http://dx.doi.org/10.1111/0026-7902.00016

Shany, M., Ben Dror, I., \& Zeiger, T. (1997). Tests for Reading and Writing Disabilities-Pioneering Stage. Scientific Publication in the Framework of the Mofet Institute and the Unit for Research and Assessment, Beit Berl (Hebrew).

Shany, M., Zeiger, T., \& Ravid, D. (2001). Development and Validity of Diagnostic Tools for the Basic Processes of Reading and Writing: Findings Regarding the Performance of Normal Readers and Suggestions for the Integration of Diagnostic Tools in the Assessment of Students with Reading Difficulties. Scrift-Oriyianut: Research, Study, and Practice, 2, 167-203 (Hebrew).

Sparks, R., \& Ganschow, L. (1993). The Impact of Native Language Learning Problems on Foreign Language Learning: Case Study Illustrations of the Linguistic Coding Deficit Hypothesis. Modern Language Journal, 77, 58-74.

Sparks, R., Ganschow, L., \& Javorsky, J. (2000). Déjà vi All Over Again: A Response to Saito, Horwitz, and Gerza. Modern Language Journal, 84, 251-255. http://dx.doi.org/10.1111/0026-7902.00066

Sparks, R., Ganschow, L., Kenneweg, S., \& Miller, K. (1991). Use of an Orton-Gillingham Approach to Teaching a Foreign Language to Dyslexic/Learning-Disabled Students: Explicit Teaching of Phonology in a Second Language. Annals of Dyslexia, 41, 96-118. http://dx.doi.org/10.1007/BF02648080

Sparks, R., Javorsky, J., Ganschow, L., Pohlman, J., \& Patton, J. (1992). Test Comparisons among Students Identified as High-Risk, Low-Risk, and Learning Disabled in High School Foreign Language Courses. Modern Language Journal, 76, 142-159. http://dx.doi.org/10.1111/j.1540-4781.1992.tb01094.x

Tobias, S. (1979). Anxiety Research in Educational Psychology. Journal of Educational Psychology, 71, 573-582. http://dx.doi.org/10.1037/0022-0663.71.5.573

Verhoeven, L., \& Vermeer, A. (2002). Communicative Competence and Personality Dimensions in First and Second Language Learners. Applied Psycholinguistics, 23, 361-374. http://dx.doi.org/10.1017/S014271640200303X

Wine, J. (1980). Cognitive-Attentional Theory of Test Anxiety. In I. G. Sarason (Ed.), Test Anxiety: Theory, Research and Applications (pp. 349-385). Hillsdale, NJ: Erlbaum.

von Wörde, R. (2003). Students' Perspectives on Foreign Language Anxiety. Inquiry (e-journal), 8.

Yamashita, J. (2004). Reading Attitudes in L1 and L2 and Their Influence on L2 Extensive Reading. Reading in a Foreign Language, 16, 1-19. 


\section{Instructions}

The questionnaire consists of 60 sentences describing various behaviors, emotions, and tenets. It is formulated in the masculine purely for purposes of convenience, covering both genders.

Please read each description carefully and mark the answer you think most appropriate with an "x.

Mark the answer "Completely disagree" when you feel that the statement does not match you at all.

Mark the answer "Disagree" when you feel that the description does not match you to a significant degree.

Mark the answer "Neutral" when the description is matches/does not match you in equal measure.

Mark the answer "Agree" when the description matches you to a significant degree.

Mark the answer "Absolutely agree" when the description matches you completely.

As in aptitude tests, there are no right or wrong answers and no special knowledge is required in order to be able to answer the questions

Answer ALL the questions. If you mark an answer and then wish to change your mind, put a line through the first answer and mark the correct answer with an $\mathrm{x}$.

With thanks for your cooperation.

\begin{tabular}{|c|c|c|c|c|c|c|}
\hline & & $\begin{array}{l}\text { Absolutely } \\
\text { agree }\end{array}$ & Agree & Neutral & Disagree & $\begin{array}{l}\text { Completely } \\
\text { disagree }\end{array}$ \\
\hline 1 & I am not a worrier & & & & & \\
\hline 2 & I like have lots of people around & & & & & \\
\hline 3 & I don't like wasting time dreaming in the summer & & & & & \\
\hline 4 & I try to be polite to everyone I meet & & & & & \\
\hline 5 & I am very organized and tidy & & & & & \\
\hline 6 & I frequently feel inferior to other people & & & & & \\
\hline 7 & I laugh very easily & & & & & \\
\hline 8 & The moment I find a good work method, I stick to it & & & & & \\
\hline 9 & I easily pick arguments with family members or friends at work & & & & & \\
\hline 10 & I know how to adopt a work pace that guarantees I finish in time & & & & & \\
\hline 11 & $\begin{array}{c}\text { When I'm very stressed I sometimes feel } \\
\text { I'm about to have a breakdown }\end{array}$ & & & & & \\
\hline 12 & I don't think I'm a particularly cheerful or carefree person & & & & & \\
\hline 13 & Patterns in art or nature arouse my curiosity & & & & & \\
\hline 14 & Some people regard me as selfish and self-centered & & & & & \\
\hline 15 & I'm not the most systematic person in the world & & & & & \\
\hline 16 & I virtually never feel lonely or depressed & & & & & \\
\hline 17 & I really enjoy talking to people & & & & & \\
\hline 18 & $\begin{array}{l}\text { I believe that letting students listen to controversial } \\
\text { speeches only confuses and misleads them }\end{array}$ & & & & & \\
\hline 19 & I prefer to collaborate than to compete with people & & & & & \\
\hline 20 & I try to carry out every task I'm given very carefully & & & & & \\
\hline 21 & I'm frequently nervous and stressed & & & & & \\
\hline 22 & I like being in places which have moving experiences & & & & & \\
\hline 23 & I'm not really moved (or aren't moved at all) by written poetry & & & & & \\
\hline 24 & $\begin{array}{l}\text { I'm inclined to be cynical and skeptical about } \\
\text { other people's motives/intentions }\end{array}$ & & & & & \\
\hline 25 & $\begin{array}{l}\text { I have a clear set of goals and work in an } \\
\text { organized fashion to accomplish them }\end{array}$ & & & & & \\
\hline
\end{tabular}




\section{Continued}

I sometimes feel that I have no self-worth

I generally prefer to do things alone

I often try new and unfamiliar foods

I believe that, if you allow them, most people will exploit you

I waste a lot of time before I start concentrating at work

I'm virtually never afraid or anxious

I frequently feel that I'm full of energy

I virtually never pay attention to moods or emotions aroused by different situations

Most of the people I know like me

I work very hard to accomplish my goals

I'm sometimes upset by the way in which people relate to me

I'm a cheerful and vibrant person

I believe we have consult the religious authorities in order to receive decisions in moral matters

Some people think I am cunning and cold-hearted

When I say I'll do something you can trust that I'll do it

Too often, when things are going right, I get disappointed and want to give up

I'm not a cheerful optimist

Sometimes when I read a poem of look at a piece of art I get goose bumps or feel a wave of emotion

I am decisive and firm in my opinions

At times I'm not as reliable or trustworthy as I would like to be

I virtually never feel sad or depressed

I live life at a fast pace

I'm not very interested in thinking about the world or the human condition

I usually try to be considerate of others

I'm a creative person who carries out things to the end

I frequently feel helpless and want other people to solve my problems

I'm an extremely active person

I have a very high level of intellectual curiosity

When I don't like people I tell them so

I don't think I'll ever be an organized person

It's happened that I've been so

embarrassed that I've wanted to hide

I prefer to go my own way rather than be a leader of others

I often like to play around with legal ideas and theories

When necessary, I'm prepared to influence and manipulate others in order to get what I want 